\title{
Receita caseira para eliminar piolho: superstição ou ciência?
}

Homemade recipe to eliminate lice: superstition or science?

Sabrina Sonegheti ${ }^{1}$, Elisa Mitsuko Aoyama ${ }^{2}$

${ }^{1}$ Programa de Pós-Graduação em Rede em Ensino de Biologia (PROFBIO), Universidade Federal do Espírito Santo, São Mateus, Espírito Santo, Brasil.

${ }^{2}$ Universidade Federal do Espírito Santo, Departamento de Ciências Agrárias e Biológicas, São Mateus, Espírito Santo, Brasil.

Autor para correspondência: Sabrina Sonegheti

EEEM Emir de Macedo Gomes

Avenida São Mateus, 1679, Bairro Shell, CEP 29.901-630, Linhares, Espírito Santo, Brasil

Tel: +55 27995739952

Email: ssonegheti@gmail.com

\section{Submetido em 21/12/2020}

Aceito em 21/12/2020 


\title{
RESUMO
}

O trabalho trata-se de uma proposta de atividade investigativa sobre o tema Botânica para as aulas de Biologia do ensino médio, tendo como objetivo promover a educação científica a partir da comparação de uma superstição com o saber científico produzido sobre a mesma, realizando uma pesquisa em literatura científica, por meio da abordagem investigativa, sobre as propriedades da planta Ruta graveolens L. (arruda) na eliminação de piolhos. Apresenta metodologia detalhada e informações sobre como explorar a atividade numa abordagem investigativa.

Palavras-chave: Biologia. Botânica. Ectoparasito. Atividade Investigativa. Ensino.

\begin{abstract}
The work is a proposal for an investigative activity on the subject of Botany for high school Biology classes with the objective of promoting scientific education from the comparison of a superstition with the scientific knowledge produced on it, carrying out a research in scientific literature, through the investigative approach, on the properties of the plant Ruta graveolens L. (rue) in the elimination of lice. It presents detailed methodology and information on how to explore the activity in an investigative approach.
\end{abstract}

Keywords: Biology. Botany. Ectoparasite. Investigative Activity. Teaching.

Health and Biosciences, v.1, n.3, Dez. 2020

Disponível em: https://periodicos.ufes.br/healthandbiosciences 


\section{INTRODUÇÃO}

A relação entre os homens e as plantas é antiga. Com o tempo, passou de coletor para cultivador, dominando e aprimorando não só técnicas de manejo do solo, da água e das plantas, mas também identificando nelas diferentes características e usos além do alimentar, como o recreativo, ornamental, cosmético e medicamentoso, dentre outros. Do mesmo modo, a relação entre os homens e os animais também é antiga, ora como caçador/predador, alimentando-se desses, ora dominando e aprimorando as técnicas de criação dos animais.

Assim como as relações mencionadas, o saber popular foi produzido, transformado e transmitido através das gerações, desde a antiguidade. Esse saber relaciona-se com os povos, suas culturas e com a fauna e a flora, seja da região onde vivem, seja aquela apropriada de outros povos e culturas e deve ser, sempre que possível, valorizado pelos professores em suas aulas, não como conhecimento acabado, mas como conhecimento útil na contextualização das matérias e conteúdo a serem estudados. Paulo Freire (1987) destaca a importância da problematização a partir da vivência dos educandos, de modo a valorizar, com respeito, seus conhecimentos cotidianos. O autor ainda argumenta que não devemos desconsiderar ou descartar a compreensão dos estudantes sobre o mundo diante do conhecimento científico, aproveitando os conhecimentos cotidianos dos educandos na busca por novos conhecimentos, mais elaborados (FREIRE, 1992).

Associando o pensamento de Paulo Freire com o Ensino por Investigação (CARVALHO, 2013; PEDASTE et al., 2015; SASSERON, 2015; SÁ et al., 2017) é possível promover uma educação científica inclusiva e atraente aos estudantes, uma educação que ao mesmo tempo que valoriza seus conhecimentos prévios dá a eles a chance de serem protagonistas na construção do próprio saber. A Base Nacional Comum Curricular, BNCC (BRASIL, 2017) evidencia isso nas seguintes competências gerais da educação básica:

1. Valorizar e utilizar os conhecimentos historicamente construídos sobre o mundo físico, social, cultural e digital para entender e explicar a realidade, continuar aprendendo [...].

2. Exercitar a curiosidade intelectual e recorrer à abordagem própria das ciências, incluindo a investigação, a reflexão, a análise crítica, a imaginação e a criatividade, para investigar causas, elaborar e testar hipóteses, formular e resolver problemas e criar soluções (inclusive tecnológicas) com base nos conhecimentos das diferentes áreas.

$[\ldots]$

6. Valorizar a diversidade de saberes e vivências culturais e apropriar-se de conhecimentos e experiências que lhe possibilitem entender as relações próprias do mundo do trabalho e fazer escolhas alinhadas ao exercício da cidadania e ao seu

Health and Biosciences, v.1, n.3, Dez. 2020

Disponível em: https://periodicos.ufes.br/healthandbiosciences 
projeto de vida, com liberdade, autonomia, consciência crítica e responsabilidade.

7. Argumentar com base em fatos, dados e informações confiáveis, para formular, negociar e defender ideias, pontos de vista e decisões comuns [...].

Diante da necessidade de inserir o ensino por investigação na prática diária discente e com o intuito de promover, sempre que possível, uma educação científica que valorize a ciência e o método científico, ao mesmo tempo que também valoriza os saberes e interesses dos estudantes, apresenta-se aqui uma atividade investigativa de pesquisa em literatura científica sobre o potencial piolhicida da planta arruda.

\section{OBJETIVOS}

$\checkmark$ Promover a educação científica a partir da comparação de uma superstição com o saber científico produzido sobre a mesma.

$\checkmark$ Realizar pesquisa em literatura científica, por meio da abordagem investigativa, sobre as propriedades da planta Ruta graveolens L. (arruda) na eliminação de piolhos.

\section{METODOLOGIA}

\section{Materiais utilizados}

A atividade proposta deve ser vista como um exemplo flexível e modificável, de acordo com os saberes populares de interesse do professor e dos estudantes. Nesse exemplo serão utilizados:

- Bilhete escolar com uma "Receita caseira para eliminar piolhos";

- Raiz, caule e folha de Ruta graveolens L. (arruda);

- Preparado (infusão) a partir das folhas de Ruta graveolens L. (arruda);

- Smartphone, tablet e/ou computador com acesso à internet;

- Livros sobre plantas medicinais.

A planta, suas partes e a infusão serão utilizadas para observação e análise das propriedades organolépticas. Smartphone, tablet e/ou computador serão utilizados nas pesquisas realizadas em meio virtual (sites diversos a partir do buscador Google e Google Scholar). Os livros serão utilizados nas pesquisas físicas, principalmente para estudo das características específicas da espécie. Sobre os livros, faz-se uma ressalva: é necessário escolher

Health and Biosciences, v.1, n.3, Dez. 2020

Disponível em: https://periodicos.ufes.br/healthandbiosciences 
títulos de confiança acadêmico-científica. Indica-se o livro Plantas Medicinais no Brasil Nativas e Exóticas, de Harri Lorenzi e Francisco J. de Abreu Matos.

A atividade deve ser pautada no Ensino por Investigação (CARVALHO, 2013; PEDASTE et al., 2015; SASSERON, 2015; SÁ et al., 2017) e nas fases do ciclo investigativo determinadas por Pedaste et al. (2015).

\section{Desenvolvimento}

A atividade pode ser realizada com estudantes de qualquer série do Ensino Médio e, até mesmo, desde que adaptada, com estudantes do Ensino Fundamental. Recomenda-se que o professor reserve três aulas para sua realização. O elemento motivador dessa atividade é um bilhete escolar infantil contendo uma "receita caseira para eliminar piolho" (Figura 1).

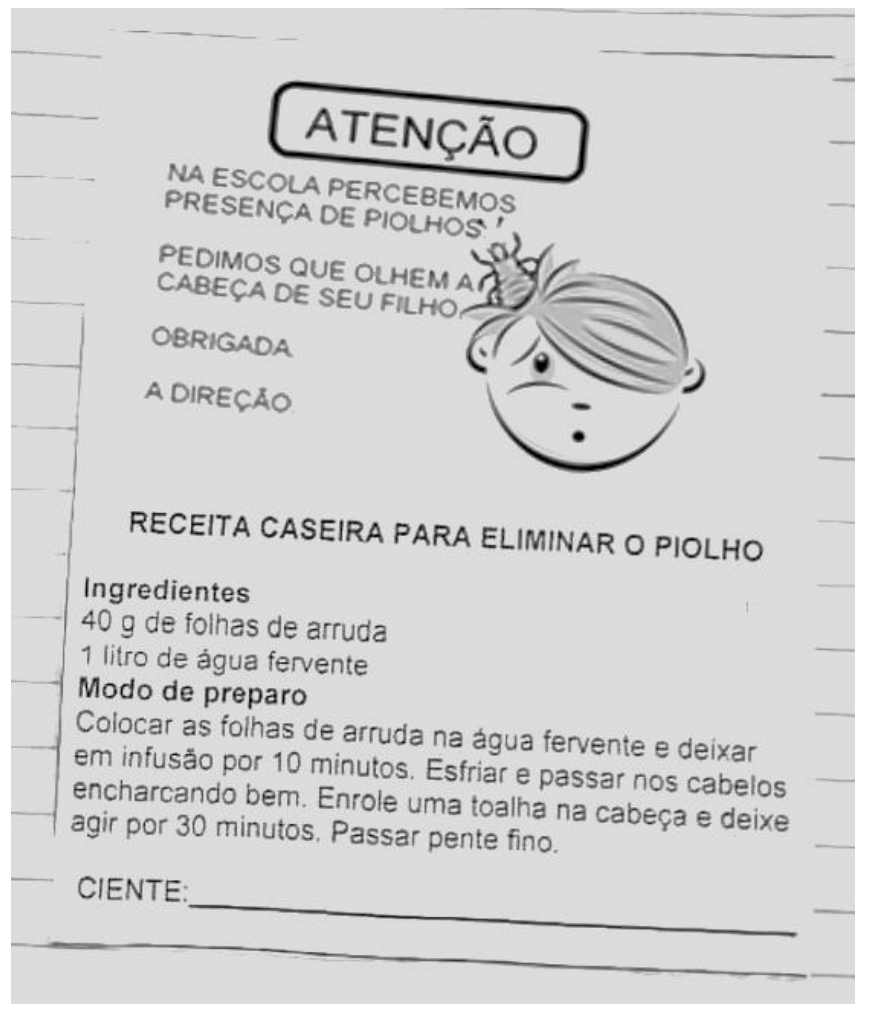

Figura 1. Bilhete escolar com a "receita caseira para eliminar piolho".

Na primeira aula o professor deve usar o bilhete com criatividade, contextualizando-o da maneira que lhe for mais adequada. Recomenda-se que conte uma história que envolva os estudantes e os faça relembrar de sua infância e de seus familiares.

Espera-se que os estudantes conversem entre si sobre o assunto do bilhete com base em

Health and Biosciences, v.1, n.3, Dez. 2020

Disponível em: https://periodicos.ufes.br/healthandbiosciences 
suas vivências, crenças e conhecimentos prévios, que podem variar desde o total desconhecimento sobre a planta em questão e seus usos até a troca de outras receitas e métodos que julguem eficazes contra infestações de piolhos. O professor deve aproveitar esse momento de troca de experiências para além da problematização, fazendo com que os estudantes reflitam sobre a real eficácia da receita, comparando o saber popular com o conhecimento científico.

Nesse primeiro momento deve-se estimular a curiosidade dos estudantes para as próximas fases da atividade, por meio da definição de um problema de pesquisa. Recomendase que o problema trate da real eficácia da receita do bilhete, se ela é pautada na ciência ou se é apenas uma crendice popular, uma superstição, se funciona ou não funciona para eliminar piolhos. De posse do problema, os estudantes devem ser orientados a formular questões de pesquisa que ajudem a resolver o problema, bem como a escrever suas respostas provisórias (hipóteses) para as questões formuladas por eles próprios.

$\mathrm{Na}$ aula seguinte, os estudantes devem iniciar uma ampla busca em meio virtual (Google e Google Scholar) e em livros, preferencialmente oriundos da biblioteca da própria escola. Durante a busca devem ser orientados a coletar dados e resultados de pesquisas científicas que ajudem a responder as questões formuladas na aula anterior. É indicado que o professor acompanhe as buscas para garantir que ocorram em sites confiáveis, ou seja, de instituições de pesquisa, universidades, revistas, periódicos etc. Os resultados coletados devem ser analisados, interpretados e discutidos entre os estudantes e com a professor em busca de respostas conclusivas. Nesse momento, os estudantes devem revisitar suas respostas provisórias, a fim de confirmá-las ou refutá-las.

$\mathrm{Na}$ terceira aula, com o objetivo de garantir o reconhecimento da planta estudada por meio da observação e dos sentidos, os estudantes devem analisar as características organolépticas da arruda (R. graveolens L.) em si, suas partes (raiz, caule e folhas) e da infusão das folhas preparada conforme a receita do bilhete. Enquanto interagem devem ser estimulados a discutir e refletir sobre o papel da ciência na desmistificação de crenças e superstições comuns do saber popular. Espera-se que discutam sobre as etapas do método científico e sobre a necessidade da realização de pesquisas - como a que fizeram e também as realizadas por cientistas - antes de afirmações serem feitas acerca de um determinado tema, como a eficácia de um produto ou medicamento. 


\section{PONTOS INVESTIGATIVOS DA ATIVIDADE}

A atividade proposta valoriza a curiosidade e os interesses, bem como o contexto social e cultural dos estudantes. Durante seu desenvolvimento os estudantes serão protagonistas da investigação, fazendo coleta, análise e interpretação de dados, discussão, conclusão e comunicação, construindo uma nova relação de conhecimento com o saber popular existente. Nesse caminho terão a oportunidade de refletir sobre a própria atividade e o processo de construção da ciência.

Com base no exposto é evidente o caráter investigativo da atividade, conforme já relatado por diversos autores (CARVALHO 2013; PEDASTE et al., 2015; SASSERON, 2015; SÁ et al., 2017). Também é possível evidenciar que a atividade atende, parcialmente, aos requisitos dos três eixos estruturantes da Alfabetização Científica.

Além disso, a atividade proposta contempla três habilidades da BNCC (BRASIL, 2017) para o Ensino Médio, que tratam, em resumo:

- Da construção de questões, elaboração de hipóteses, previsões e estimativas, medição e interpretação de dados e/ou resultados para construção, avaliação e conclusões no enfrentamento de situações-problema sob uma perspectiva científica;

- Da interpretação de textos, gráficos, tabelas, por meio de diferentes linguagens, mídias, tecnologias digitais de informação e comunicação (TDIC), de modo a participar e/ou promover debates em torno de temas científicos e/ou tecnológicos de relevância sociocultural e ambiental;

- Da interpretação de textos de divulgação científica que tratem de temáticas das Ciências da Natureza, disponíveis em diferentes mídias, considerando a apresentação dos dados, tanto na forma de textos como em equações, gráficos e/ou tabelas, a consistência dos argumentos e a coerência das conclusões, visando construir estratégias de seleção de fontes confiáveis de informações.

\section{CONSIDERAÇÕES}

O conteúdo dessa atividade não é restrito ao proposto, pois o professor pode se aproveitar de dúvidas variadas dos estudantes para conduzir uma atividade similar, desde que respeite as fases/etapas básicas do Ensino por Investigação.

A partir da pergunta norteadora, das perguntas secundárias, das respostas provisórias

Health and Biosciences, v.1, n.3, Dez. 2020

Disponível em: https://periodicos.ufes.br/healthandbiosciences

pág. 140 
formuladas pelos estudantes, das respostas encontradas, da discussão e da conclusão, outros questionamentos podem ser formulados e discutidos por eles. Por isso, apesar de sua aparente simplicidade, acredita-se que a atividade proposta é capaz de beneficiar a prática docente.

Avaliando a atividade, destacam-se os seguintes pontos positivos:

- A problematização inicial e a escolha do tema podem partir dos próprios estudantes;

- O tema - crendices e superstições - faz parte do saber popular;

- A pesquisa em meio virtual é acessível, podendo ser realizada praticamente em qualquer lugar e horário;

- O custo para realização da atividade é baixo;

- A atividade pode ser feita em poucas aulas.

Negativamente, aponta-se a ausência de experimentação. Porém, caso o professor aplicador tenha a sua disposição os recursos e espaço adequados, pode realizar experimentos básicos de botânica, tais como: preparação de exsicatas, utilização de diferentes métodos de extração, separação de pigmentos através de cromatografia em papel, extração de óleo essencial, preparação de cortes histológicos, dentre outros.

\section{AGRADECIMENTOS}

O presente trabalho foi realizado com o apoio da Coordenação de Aperfeiçoamento de Pessoal de Nível Superior - Brasil (CAPES) - Código de financiamento 001.

\section{REFERÊNCIAS BIBLIOGRÁFICAS}

1. BRASIL. Base Nacional Comum Curricular (BNCC). Educação é a Base. Brasília: MEC/CONSED/UNDIME, 2018. Disponível em: $<$ http://basenacionalcomum.mec.gov.br/images/BNCC_EI_EF_110518_versaofinal_site. pdf $>$. Acesso em 12 de junho de 2020.

2. CARVALHO AMP, OLIVEIRA CMA, SCARPA DL, SASSERON LH, SEDANO L, BATISTONI e SILVA M, CAPECCHI MCVM, ABIB MLVS, BRICCIA V. Ensino de 
Ciências por Investigação: Condições de implementação em sala de aula, São Paulo: Cengage Learning, 2013, 164p.

3. FREIRE P. Pedagogia do Oprimido, 17.ed., Rio de Janeiro: Paz e Terra, 1987, 184p.

4. FREIRE P. Pedagogia da esperança: um reencontro com a pedagogia do oprimido, 2.ed., Rio de Janeiro: Paz e Terra, 1992, 245p.

5. PEDASTE M, MÄEOTS M, SIIMAN LA, DE JONG T, VAN RIESEN SAN, KAMP ET, MANOLI CC. Phases of inquiry-based learning: Definitions and the inquiry cycle. Educ Res Rev 14: 47-61, 2015.

6. SÁ EF, FIGUEIREDO E PAULA H, LIMA MECC, AGUIAR OG. As características das atividades investigativas segundo tutores e coordenadores de um curso especialização em ensino de ciências. Disponível em: <http://www.nutes.ufrj.br/abrapec/vienpec/CR2/p820.pdf>. Acesso em 1 de dezembro de 2019.

7. SASSERON LH. Alfabetização científica, ensino por investigação e argumentação: relações entre ciências da natureza e escola. Rev Ensaio 17: 49-67, 2015. 